ISSN = 1980-993X - doi:10.4136/1980-993X
Www.ambi-agua.net
E-mail: ambi-agua@agro.unitau.br
Tel.: (12) 3625-4212

\title{
Influência da presença de camada de resíduos de construção civil na remoção de metais pesados em percolado recirculado de aterro sanitário
}

(doi:10.4136/ambi-agua.139)

\author{
Katia Gonçalves Gutierrez'; Antonio Teixeira de Matos²; Maike Rossmann² \\ ${ }^{1}$ IEAA - Instituto de Educação, Agricultura e Ambiente - UFAM \\ E-mail: katiaggutierrez@hotmail.com \\ ${ }^{2}$ IEAA - Departamento de Engenharia Agrícola e Ambiental - UFV \\ E-mail: atmatos@ufv.br; maikersm@gmail.com
}

\section{RESUMO}

Pouco se sabe sobre a capacidade do material orgânico estabilizado (RSU velho) e do resíduo de construção civil (RCC) em reter metais pesados contidos em percolados gerados em aterros sanitários. Objetivou-se avaliar a capacidade do RSU velho em remover metais pesados presentes em percolado produzido por RSU recém coletado, além do efeito do RCC na concentração de metais pesados no efluente de colunas de RSU velho. Em três colunas (CR), colocou-se uma camada de RCC e, em seguida, RSU velho e em três (SR), apenas RSU velho. Analisaram-se, no percolado e no efluente, $\mathrm{pH}, \mathrm{CE}, \mathrm{DBO}$ e os metais $\mathrm{Zn}, \mathrm{Cd}, \mathrm{Cu}$ e $\mathrm{Pb}$. Houve eficiente e semelhante remoção de DBO e metais pesados em ambos os tratamentos. A presença da camada de RCC mostrou-se importante para a melhoria geral na qualidade do efluente, porém não influenciou a concentração de metais nele. A ordem de retenção dos metais nas colunas foi: $\mathrm{Cu} \sim \mathrm{Pb}>\mathrm{Cd}>\mathrm{Zn}$. À exceção do $\mathrm{Cd}$ e do $\mathrm{Zn}$, todas as outras variáveis avaliadas nos efluentes estiveram abaixo dos padrões máximos estabelecidos na DN 01/08 COPAM/CERH para lançamento de efluente em corpo hídrico.

Palavras-chave: capacidade de retenção; chorume; elementos traço.

\section{Influence of the civil construction debris layer in heavy metals removal of the leachate submitted to recirculation in landfill}

\section{ABSTRACT}

Little is known about the ability of stabilized organic matter (old MSW) and construction waste (RCC) to retain heavy metals from leachate generated in landfills. The objective of this study was to assess the potential of MSW to remove old heavy metals in MSW leachate produced by freshly collected, and the effect of RCC in the concentration of heavy metals in effluents from MSW old. In three columns (CR), put a layer of RCC and then MSW old and, on the other three (SR), only MSW old. Analyzed in the leachate and effluent pH, EC, BOD and metals $\mathrm{Zn}, \mathrm{Cd}, \mathrm{Cu}$ and $\mathrm{Pb}$. There were similar and efficient removal of BOD and heavy metals in both treatments. The presence of the layer of RCC was considered important to the overall improvement in effluent quality, but did not influence the concentration of metals in the effluent. The order of retention of metals in the columns was: $\mathrm{Cu} \sim \mathrm{Pb}>\mathrm{Cd}>\mathrm{Zn}$. With the exception of $\mathrm{Cd}$ and $\mathrm{Zn}$, all other variables assessed in the effluent were below the maximum standards set in DN 01.08 COPAM / CERH for release effluent into water bodies.

Keywords: retention capacity; landfill leachate; trace elements. 
GUTIERREZ, K. G.; MATOS, A. T.; ROSSMANN, M. Influência da presença de camada de resíduos de construção civil na remoção de metais pesados em percolado recirculado de aterro sanitário. Ambi-Agua, Taubaté, v. 5, n. 2, p. 87-98, 2010. (doi:10.4136/ambi-agua.139)

\section{INTRODUÇÃO}

Dentre as alternativas tecnológicas para disposição de resíduos sólidos urbanos (RSU), o aterro sanitário ainda é a técnica mais utilizada (Leahy e Shreve, 2000), pois apresenta menor custo (D’Almeida e Vilhena, 2000) e, comparativamente a outras técnicas, menores impactos (Junkes, 2002).

Com a degradação do material orgânico presente no RSU, há a geração do chorume, um líquido escuro, de alta carga orgânica e inorgânica e de elevado impacto ambiental. Em razão da infiltração de água de chuva no material acondicionado no aterro há a mistura dessas águas com o chorume produzido, gerando o que se denomina "percolado". O tratamento e a disposição final desse percolado é, ainda hoje, um dos principais problemas ambientais gerados nessa atividade.

O tratamento do percolado coletado é atividade complexa que requer a instalação de sistemas que proporcionem redução da carga orgânica e de outros poluentes presentes neste. Entre os componentes inorgânicos presentes no percolado de aterro sanitário estão os metais pesados, tais como cobre, chumbo e zinco que, considerando-se os riscos que proporcionam ao meio físico e biótico, devem ser monitorados com atenção (Silva, 2002).

A recirculação do percolado em células de lixo tem sido apontada como técnica de grande viabilidade no tratamento desses resíduos, por possibilitar o prolongamento da vida útil dos aterros sanitários, tornar desnecessária a construção de uma unidade de tratamento para este líquido e, principalmente, por reduzir significativamente os componentes orgânicos e inorgânicos presentes - em razão da ocorrência de processos de adsorção, precipitação, quelação/complexação, que ocorrem quando há contato do líquido com o material aterrado.

A solubilidade dos metais no percolado depende do $\mathrm{pH}$, do potencial redox e da solubilidade das espécies iônicas dos metais presentes neste, da concentração de agentes complexantes (ácidos húmicos) e da força iônica da solução (Erses e Onay, 2003). Segundo os mesmos autores, a solubilidade dos metais no percolado aumenta com o decréscimo do $\mathrm{pH}$, observando-se ampliação na concentração de metais no percolado quando os valores de $\mathrm{pH}$ estão mais baixos. Em vista disso, a recirculação do percolado em meio básico pode reduzir a concentração de metais pesados no líquido filtrado. Uma forma de possibilitar a passagem do percolado em meio básico é a disposição de uma camada de resíduos de construção civil (RCC) junto à base das células de disposição do RSU (Sousa et al., 2002). O uso do RCC com essa finalidade, além de reduzir as concentrações de metais pesados no percolado, tem reduzido o problema gerado pelo elevado volume de entulhos gerados na construção civil.

A interação de metais pesados e diferentes componentes da fração sólida do solo têm sido bastante estudadas, porém, pouco se sabe sobre a capacidade do material orgânico do RSU estabilizado e do RCC em reter metais pesados presentes em percolados gerados em aterros sanitários, conhecimento indispensável quando se faz a recirculação do percolado (Matos et al., 2009).

Neste sentido, os objetivos deste trabalho foram avaliar a capacidade do material orgânico estabilizado (RSU velho - aterrado por 20 anos), em remover metais pesados presentes no percolado produzido por material orgânico novo (RSU novo - recém- coletado), além de avaliar o efeito da presença da camada de resíduo de construção civil (RCC) sobre a concentração de metais pesados no efluente de células experimentais preenchidas com RSU velho.

\section{MATERIAIS E MÉTODOS}

O experimento foi conduzido na Área Experimental de Tratamento de Resíduos Urbanos do Departamento de Engenharia Agrícola, Universidade Federal de Viçosa, Viçosa, MG. Para

o desenvolvimento das atividades de pesquisa, foram construídas seis colunas para 
GUTIERREZ, K. G.; MATOS, A. T.; ROSSMANN, M. Influência da presença de camada de resíduos de construção civil na remoção de metais pesados em percolado recirculado de aterro sanitário. Ambi-Agua, Taubaté, v. 5, n. 2, p. 87-98, 2010. (doi:10.4136/ambi-agua.139)

representar células de um aterro sanitário. Cada coluna foi constituída por três manilhas de concreto armado, com 1,00 m de diâmetro interno e 1,00 m de altura, sobrepostas e seladas na junção com argamassa de cimento, formando um cilindro rígido de 3,00 m de altura (Figura 1).

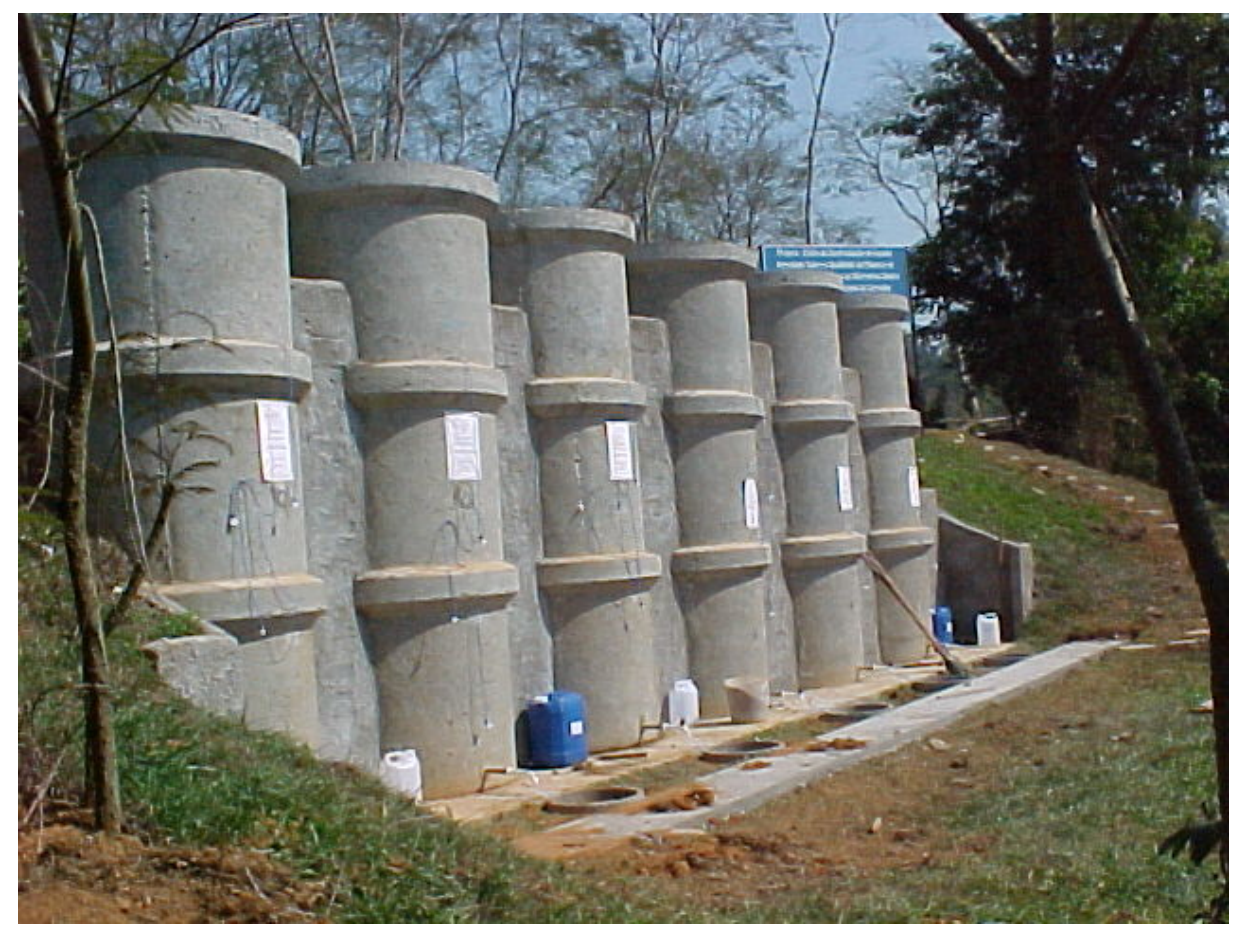

Figura 1. Vista geral das colunas experimentais.

O resíduo de construção civil (RCC), colocado na base de três colunas, foi coletado em demolição localizada próxima ao Departamento de Engenharia Agrícola, sendo constituído, predominantemente, por material resultante da derrubada de paredes.

A camada de drenagem posicionada na base de cada uma das colunas experimentais, de 0,10 $\mathrm{m}$ de espessura, foi composta por 0,07 $\mathrm{m}$ de brita $\mathrm{n}^{\circ} 1$ e $0,03 \mathrm{~m}$ de areia grossa. Sobre a camada de drenagem, três colunas experimentais receberam uma camada de 0,30 $\mathrm{m}$ de espessura de RCC, composto por material de tamanho variando entre 0,5 cm e 3,0 cm. Acima da camada de drenagem, no caso das colunas que não receberam a camada de RCC (colunas SR), e da camada de RCC, nas colunas que a receberam (colunas CR), foram acondicionadas, sequencialmente, camadas de RSU velho, com cerca de 20 anos de idade de aterramento, coletado no lixão do Município de Visconde do Rio Branco, MG. Ao fim do enchimento das colunas experimentais, os pesos específicos encontrados foram de $14 \mathrm{kN} \mathrm{m}^{-3}$ nas colunas SR e de $13,19 \mathrm{kN} \mathrm{m}^{-3}$ nas colunas CR. No topo das colunas experimentais, sobre a camada de resíduos sólidos, foi colocada uma camada de $0,15 \mathrm{~m}$ de brita $\mathrm{n}^{\circ}$. 1 e sobreposta uma camada de 0,20 m de areia grossa para possibilitar melhor distribuição do percolado no processo de recirculação.

Para produção do percolado a ser recirculado nas células de aterro sanitário, foi utilizado um reservatório de fibra de vidro com capacidade para 10.000 litros. O preenchimento do reservatório produtor de percolado deu-se de forma que, aproximadamente, 2/3 do seu volume foi preenchido com o RSU recém-coletado na cidade de Viçosa, estabelecendo um peso específico de $7 \mathrm{kN} \mathrm{m}^{-3}$. Para proteger os tubos de drenagem de possíveis entupimentos, estes foram cobertos com telas plásticas de malha de $1,0 \mathrm{~cm}$ x $1,0 \mathrm{~cm}$. Logo após o acondicionamento de todo o RSU, foi sobreposta uma camada de cobertura composta de 0,15 $\mathrm{m}$ de brita $\mathrm{n}^{\circ} .1$, seguida por uma camada de $0,20 \mathrm{~m}$ de areia grossa, a fim de facilitar a 
GUTIERREZ, K. G.; MATOS, A. T.; ROSSMANN, M. Influência da presença de camada de resíduos de construção civil na remoção de metais pesados em percolado recirculado de aterro sanitário. Ambi-Agua, Taubaté, v. 5, n. 2, p. 87-98, 2010. (doi:10.4136/ambi-agua.139)

distribuição das precipitações natural e artificial, evitando transbordamentos. Tanto as células experimentais quanto o reservatório produtor de percolado contendo RSU recém- coletado foram construídos de forma a ficarem parcialmente enterrados.

A composição gravimétrica do RSU utilizado no preenchimento da célula produtora de percolado está apresentada na Tabela 1. Não foi possível fazer a caracterização física e a composição gravimétrica do RSU velho, devido ao seu avançado estado de decomposição.

Tabela 1. Composição gravimétrica do resíduo sólido urbano da cidade de Viçosa - MG utilizado no experimento.

\begin{tabular}{l|c|c}
\hline Componentes & Massa (kg) & Percentual \\
\hline Papel & 25,7 & 7,14 \\
Papelão & 15,0 & 4,17 \\
Plástico duro & 9,2 & 2,55 \\
Plástico filme & 56,8 & 15,77 \\
PET & 3,2 & 0,89 \\
Vidro & 13,2 & 3,67 \\
Alumínio & 1,0 & 0,28 \\
Metais & 2,5 & 0,69 \\
Tecidos & 6,7 & 1,86 \\
Resíduo orgânico & 223,3 & 62,01 \\
Outros & 3,5 & 0,97 \\
\hline TOTAL & $\mathbf{3 6 0 , 1}$ & $\mathbf{1 0 0 , 0 0}$ \\
\hline
\end{tabular}

Nas semanas em que não ocorreram chuvas, foram aplicadas lâminas médias de $5 \mathrm{~mm}$ de água, por vez, sobre o reservatório contendo RSU novo. As aplicações foram realizadas com o uso de um regador de jardim, de forma a se obter produção regular de percolado durante todo o período experimental, possibilitando, assim, a recirculação nas unidades experimentais.

O percolado, antes de sua recirculação, foi enriquecido com cádmio, zinco, cobre e chumbo. Essa solução foi preparada utilizando-se sais de nitrato desses elementos químicos, dissolvidos em água deionizada. As concentrações foram escolhidas com base nas concentrações médias de metais pesados encontradas na literatura para aterros sanitários. A solução contaminante foi preparada de tal maneira que cada mililitro adicionado em um litro de percolado aumentava a concentração natural desses metais no percolado em aproximadamente 10 vezes. Após o enriquecimento com metais pesados, o percolado foi aplicado semanalmente, de forma uniforme, sobre as colunas experimentais. As aplicações ocorreram durante um período de 17 semanas.

As análises físicas, químicas e bioquímicas do percolado e do efluente das colunas experimentais foram realizadas em intervalos de 21 dias, para avaliar o comportamento de algumas variáveis ( $\mathrm{pH}, \mathrm{CE}, \mathrm{DBO}$ e os metais $\mathrm{Zn}, \mathrm{Cd}, \mathrm{Cu}$ e $\mathrm{Pb}$ ), ao longo do período de experimentação. Para realização das análises, seguiu-se metodologia apresentada no Standard Methods for the Examination of Water and Wastewater (AWWA/APHA/WEF, 2005), para a quantificação da concentração total de metais pesados, realizou-se prévia digestão nítricoperclórica das amostras. 
GUTIERREZ, K. G.; MATOS, A. T.; ROSSMANN, M. Influência da presença de camada de resíduos de construção civil na remoção de metais pesados em percolado recirculado de aterro sanitário. Ambi-Agua, Taubaté, v. 5, n. 2, p. 87-98, 2010. (doi:10.4136/ambi-agua.139)

\section{RESULTADOS E DISCUSSÃO}

Os resultados das análises físicas, químicas e bioquímicas do percolado e do efluente das colunas experimentais, contendo ou não a camada de RCC, encontram-se apresentados na Tabela 2.

Tabela 2. Propriedades físicas, químicas e bioquímicas do percolado e do efluente das colunas experimentais.

\begin{tabular}{|c|c|c|c|c|c|c|c|}
\hline & $\mathbf{p H}^{*}$ & $\mathbf{C E}^{*}$ & $\mathbf{D B O}_{5}{ }^{*}$ & $\mathbf{P b}^{*}$ & $\mathbf{C u}^{*}$ & $\mathbf{C d}^{*}$ & $\mathbf{Z n}^{*}$ \\
\hline & & $\mathrm{dS} \mathrm{m}^{-1}$ & \multicolumn{5}{|c|}{--------------------------------- mg L } \\
\hline Afluente $^{1}$ & 5,60 & 10,98 & $17.139,29$ & 1,52 & 14,80 & 0,45 & 172,73 \\
\hline Efluente $\mathrm{CR}^{2}$ & 7,66 & 3,32 & 93,09 & 0,03 & 0,57 & 0,29 & 246,59 \\
\hline Efluente $\mathrm{SR}^{3}$ & 7,70 & 4,32 & 75,94 & 0,02 & 0,53 & 0,27 & 139,23 \\
\hline
\end{tabular}

*valores médios;

${ }^{1}$ percolado produzido pelo RSU novo no reservatório produtor;

${ }^{2}$ percolado das colunas experimentais preenchidas com RSU velho com camada de RCC;

3 percolado das colunas experimentais preenchidas com RSU velho sem camada de RCC.

O baixo valor de $\mathrm{pH}$ obtido no percolado do reservatório produtor (Tabela 2) se deve ao caráter ácido desses efluentes, formado em decorrência do RSU novo estar em estádio inicial de degradação do material orgânico, ou seja, na fase acidogênica, em que ocorre a solubilização de muitos íons. Carvalho (2005), ao trabalhar com RSU com características bastante semelhantes aos do RSU novo - recém- coletado utilizados neste trabalho, encontrou valores iniciais de $\mathrm{pH}$ muito próximos aos encontrados no reservatório produtor e mudando da condição neutra a alcalina somente a partir do $266^{\circ}$ dia de "aterramento" do RSU novo, fase não observada neste estudo devido ao menor período experimental.

A média dos valores de $\mathrm{pH}$ dos efluentes coletados nas colunas de RSU submetidas aos dois tipos de tratamento permaneceu próximo à neutralidade (Tabela 2), indicando condição de bioestabilização do material orgânico em degradação e da capacidade do sistema em elevar o pH do líquido recirculado. A capacidade tampão do sistema, proporcionado pela matéria orgânica, frente à acidez inicial, se deve aos cátions $\mathrm{Ca}^{2+}, \mathrm{Mg}^{2+}, \mathrm{K}^{+}$e $\mathrm{Na}^{+}$que são solubilizados com a mineralização ou que se encontram fracamente retidos no material orgânico (Kiehl, 1985).

Contrariando as expectativas, não foi verificado maior $\mathrm{pH}$ no efluente das colunas CR, em decorrência da presença de carbonatos e hidróxidos (presentes no cimento e na cal). Acredita-se que isso se deu devido à granulometria do RCC, que impediu maior reatividade do material com o percolado, visto que partículas maiores têm reduzido contato com o ambiente em que se encontram em função da sua pequena superfície específica.

A condutividade elétrica média no percolado bruto (afluente) foi bastante elevada (11,0

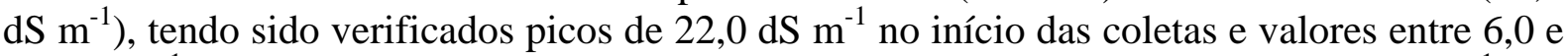

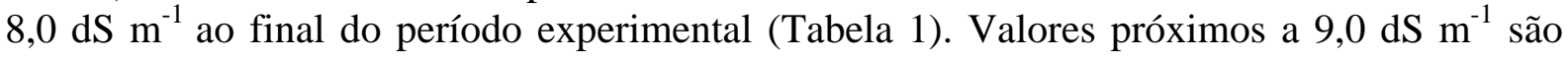
descritos para os percolados de aterros sanitários em seu primeiro ano de implantação (Qasim e Chiang,1994; Carvalho, 2005). Os elevados valores iniciais de CE podem ser decorrentes da solubilização de íons $\mathrm{NH}_{4}{ }^{+}, \mathrm{NO}_{3}{ }^{-}, \mathrm{Ca}^{2+}, \mathrm{Na}^{+}, \mathrm{K}^{+}, \mathrm{SO}_{4}{ }^{2-}$ e $\mathrm{Mg}^{2+}$, provenientes da degradação da matéria orgânica do RSU novo.

Em média, a CE no percolado produzido nas colunas de RSU submetidas ao tratamento CR foi de 3,32 dS m${ }^{-1}$ e de 4,32 $\mathrm{dS} \mathrm{m}^{-1}$ naquelas de tratamento SR (Tabela 1). Colunas de RSU com a camada de RCC possibilitaram a produção de percolado com CE $23 \%$ menor que 
GUTIERREZ, K. G.; MATOS, A. T.; ROSSMANN, M. Influência da presença de camada de resíduos de construção civil na remoção de metais pesados em percolado recirculado de aterro sanitário. Ambi-Agua, Taubaté, v. 5, n. 2, p. 87-98, 2010. (doi:10.4136/ambi-agua.139)

a obtida no percolado de colunas de RSU sem a camada de RCC. Acredita-se que esse resultado é fruto da camada de RCC que proporcionou a precipitação de íons em solução. Efeitos semelhantes foram obtidos por Carvalho (2005), que encontrou para o tratamento SR um valor médio de condutividade elétrica de $5,2 \mathrm{dS} \mathrm{m}^{-1}$ e de $4,7 \mathrm{dS} \mathrm{m}^{-1}$ no tratamento CR.

$\mathrm{A} \mathrm{DBO}_{5}$ média no afluente foi de $17.139 \mathrm{mg} \mathrm{L}^{-1}$, tendo sido iniciamente de $30.556 \mathrm{mg} \mathrm{L}^{-1}$ e, no final do período experimental, de $6.560 \mathrm{mg} \mathrm{L}^{-1}$. A faixa de variação encontrada está coerente com a reportada por Qasim e Chiang (1994), que apresentaram valores entre 7.500 e $28.000 \mathrm{mg} \mathrm{L}^{-1}$ para DBO no primeiro ano de funcionamento de aterros sanitários. Os elevados valores de $\mathrm{DBO}_{5}$ e baixos de $\mathrm{pH}$ encontrados no afluente são, tal como já comentado, característicos da fase acidogênica de degradação do material orgânico.

A recirculação do percolado proporcionou remocão significativa da $\mathrm{DBO}_{5}$, em ambos os tratamentos. O efluente das colunas CR apresentou $\mathrm{DBO}_{5}$ média de $93 \mathrm{mg} \mathrm{L}^{-1}$ e o tratamento SR média de $76 \mathrm{mg} \mathrm{L}^{-1}$, sendo o comportamento de ambos bastante uniforme durante o experimento. A maior remoção de carga orgânica no tratamento CR pode ser atribuída à maior capacidade do material de preenchimento (material orgânico estabilizado) colocado no lugar da camada de RCC (no tratamento SR), já que, aparentemente, houve pequena contribuição do RCC na remoção de DBO.

O percentual retido de metais após o balanço de massas, com o qual se relacionou a quantidade de metal afluente em uma semana com a efluente na semana subsequente está apresentado na Tabela 3.

Tabela 3. Percentual de metais pesados retido nas colunas de RSU velho contendo camada de RCC (CR) e sem a camada de RCC (SR).

\begin{tabular}{c|c|c|c|c}
\hline Metal & $\mathbf{N}^{\mathbf{1}}$ & Valor $\mathbf{p}^{\mathbf{2}}$ & Média CR (dp $\left.\mathbf{~}^{3}\right)$ & Média SR (dp $\left.^{3}\right)$ \\
\hline $\mathrm{Pb}$ & 3 & 0,27 & $94,36(4,71)$ & $97,01(1,96)$ \\
$\mathrm{Cu}$ & 3 & 0,45 & $98,65(1,17)$ & $99,30(0,65)$ \\
$\mathrm{Cd}$ & 3 & 0,51 & $78,23(18,70)$ & $87,44(11,86)$ \\
$\mathrm{Zn}$ & 3 & 0,42 & $61,71(32,06)$ & $86,34(9,87)$ \\
\hline
\end{tabular}

${ }^{1}$ número de observações para cada tratamento; ${ }^{2}$ resultado do teste de significância; ${ }^{3}$ desvio padrão.

No balanço de massas, a diferença entre os percentuais de metais retidos nas colunas de RSU não diferiu entre os tratamentos (colunas com camada de RCC e sem camada de RCC). Em termos numéricos, a retenção nesse estudo respeitou a seguinte ordem: $\mathrm{Pb} \sim \mathrm{Cu}>\mathrm{Cd}>$ Zn para os tratamento sem a camada de resíduos de construção civil e para o tratamento contendo a camada de RCC.

Entre os metais, o zinco foi o elemento que teve maior concentração no afluente enriquecido com coquetel multiespécie (Tabela 2), representando o que ocorre normalmente em situações reais, em que o elemento apresenta concentrações bem maiores que a dos demais metais estudados neste experimento. O zinco merece especial atenção não só por apresentar elevada concentração nos RSU, mas, principalmente, por sua expressiva mobilidade, quando comparada à dos outros metais.

Estudos de mobilidade têm demonstrado, no geral, que os metais $\mathrm{Pb}, \mathrm{Cr}$ e $\mathrm{Cu}$, quando dispostos sobre a superfície do solo, apresentam baixa mobilidade, enquanto $\mathrm{Mn}$, Zn, Ni e Cd são relativamente mais móveis (Fontes e Gomes, 1993; Matos et al., 1996; Nascentes, 2003).

A concentração de zinco no efluente das colunas de RSU, submetidas aos dois tratamentos, ficou bastante estável até o $70^{\circ}$ dia de experimento, ponto onde se iniciou acentuada mobilidade desse metal. $\mathrm{O}$ pico de concentração afluente ocorrido no dia 42, possivelmente, refletiu nos efluentes apenas a partir do $70^{\circ}$ dia. Enquanto que o pico ocorrido por volta do dia 98 foi instantaneamente refletido. Tal comportamento pode ser indicativo de 
GUTIERREZ, K. G.; MATOS, A. T.; ROSSMANN, M. Influência da presença de camada de resíduos de construção civil na remoção de metais pesados em percolado recirculado de aterro sanitário. Ambi-Agua, Taubaté, v. 5, n. 2, p. 87-98, 2010. (doi:10.4136/ambi-agua.139)

que a partir do $70^{\circ}$ dia o $\mathrm{Zn}$ que estava retido no afluente $(\mathrm{pH} 5,6)$ entrou em contato direto com o RSU velho (pH 7,9) e também com RCC (pH 9,3) e, ou, começou a haver substituição do Zn retido nos sítios de adsorção por elementos com maior energia de ligação. Segundo Lamim et al. (2001), a força de ligação relativa ao Zn depende da natureza da matéria orgânica, em função do pH.

O zinco, sob pH próximo a 7,7, apresentou porcentagens de retenção nas colunas CR e SR de $61,71 \%$ e $86,34 \%$, respectivamente (Tabela 3). Os resultados encontrados foram satisfatórios quando comparados aos descritos por Lamim et al. (1998), que observou que o zinco, isoladamente, apresentou 61,2\% de retenção em vermicomposto sob pH 7,5, enquanto que em competição com $\mathrm{Pb}, \mathrm{Cd}$ e $\mathrm{Cu}$, sob esse mesmo pH, a retenção foi apenas de $26,9 \%$.

A menor retenção de zinco, comparado à dos demais metais (Tabela 3), pode ser explicada também pela interferência do cobre. De acordo com estudos realizados por Matos et al. (2003) e Moreira (2004), a adsorção do Zn diminui na presença do Cu, haja vista que o Zn adsorvido à fração orgânica pode ser deslocado para a solução por cátions de maior afinidade ao material orgânico, como o $\mathrm{Cu}$ e o Pb. Outra hipótese para a dessorção de Zn e também de Cd, segundo metal menos retido nas colunas experimentais (Tabela 3), é dada por Ladonin e Margolina (1997, apud Bertoncini, 1997), que estudando interações entre ácidos húmicos e metais pesados demonstraram que a presença de cálcio, mesmo em concentração menor que $0,5 \mathrm{mg} \mathrm{L}^{-1}$, reduziu a adsorção de $\mathrm{Zn}$ e Cd. A explicação para esse fato é que o cálcio ocupa as posições de troca não específicas, diminuindo o acesso desses cátions ao complexo de troca.

No caso específico do Cádmio, a menor adsorção nas colunas CR pode ter sido influenciada pela concentração de $\mathrm{Na}_{2} \mathrm{O}$, óxido de maior abundância no RCC (Ângulo et al., 2003), uma vez que o aumento na concentração de Na no meio pode reduzir a adsorção desse metal (Omae, 1984). Essa melhor eficiência do tratamento sem a camada de RCC na retenção do metal cádmio pode ser observada nas Tabelas 2 e 3, sendo o tratamento CR 10,29\% menos eficiente em comparação ao SR. Além da diferença entre as eficiências das colunas CR e SR, o comportamento da última apresentou menor variação no percentual de lixiviação ao longo do período experimental.

Os valores de retenção encontrados para o Cd (Tabela 3) não diferiram muito dos reportados por Siqueira (1988), que encontrou em seu trabalho um percentual de retenção de 73,1\% de Cd em ácidos húmicos, sob pH 6,5. Esse autor observou, também, que a adsorção de $\mathrm{Cd}$ foi diferente da adsorção de $\mathrm{Cu}, \mathrm{Pb}$ e $\mathrm{Zn}$ nas mesmas condições experimentais. O Cd, quando estudado isoladamente, teve sua adsorção marcadamente aumentada quando o $\mathrm{pH}$ foi elevado de 4,5 a 6,0, por outro lado, a sua adsorção foi drasticamente reduzida na presença de Cu e Zn. Ainda segundo Siqueira (1988), complexos de ácidos fúlvicos e ácidos húmicos com $\mathrm{Cu}$ e $\mathrm{Pb}$ são bastante estáveis, enquanto o Cd e o Zn associam-se mais fracamente com essas substâncias.

Pelo balanço de massas, as maiores médias de remoção de metais foram relacionadas ao cobre, como apresentado na Tabela 3. A baixa dessorção do metal cobre, também verificada neste trabalho, já foi creditada e discutida por diversos autores. Harter (1979, apud Matos, 1995) considerou que o fator de maior importância para a retenção do cobre no solo seja a hidrólise de cátions, formando $\mathrm{CuOH}^{+}$, sob valores de $\mathrm{pH}$ do solo acima de 6,0, já que isto possibilitaria, em vista de menor carga iônica, adsorção de maior quantidade dessas espécies no complexo de troca. Egreja Filho (1993) creditou a diminuição da mobilidade do $\mathrm{Cu}$ à formação de humatos metálicos (quelatos) de alta estabilidade. Oliveira e Mattiazzo (2001) atribuem a adsorção do elemento à formação de complexos organometálicos, enquanto Matos et al. (1996) consideram ser a adsorção possível até mesmo em componentes do solo considerados inertes (físico-quimicamente). Para Alves (1998), os processos de adsorção de $\mathrm{Cu}$ por componentes do solo (ácidos húmicos e óxidos de $\mathrm{Fe}$ e $\mathrm{Mn}$ ) são irreversíveis ou fracamente reversíveis e requerem alta energia de ativação para dessorção, entretanto, a 
GUTIERREZ, K. G.; MATOS, A. T.; ROSSMANN, M. Influência da presença de camada de resíduos de construção civil na remoção de metais pesados em percolado recirculado de aterro sanitário. Ambi-Agua, Taubaté, v. 5, n. 2, p. 87-98, 2010. (doi:10.4136/ambi-agua.139)

elevada adsorção de íons $\mathrm{Cu}^{2+}$ pode ser apenas uma adsorção aparente, pois se acredita que altas adsorções, em valores de $\mathrm{pH}$ entre 7 e 9, podem estar relacionadas tanto com o processo de adsorção propriamente dito, como também com a precipitação do cobre, sobre a forma de $\mathrm{Cu}(\mathrm{OH})_{2}$. Embora processos químicos possam ter tido participação na remoção do $\mathrm{Cu}$, acredita-se que a remoção física do material orgânico contido no percolado tenha sido a principal razão para que se obtivessem esses resultados. Como é eficiente a remoção de material orgânico nas colunas de RSU e como o $\mathrm{Cu}$ é o metal pesado mais fortemente associado ao material orgânico, a remoção física passa a ter grande importância na remoção desse metal.

A concentração média de $\mathrm{Cu}$ no afluente foi de $14,80 \mathrm{mg} \mathrm{L}^{-1}$ e os valores médios de concentração efluente das colunas de RSU foram de $0,57 \mathrm{mg} \mathrm{L}^{-1}$ para CR e $0,53 \mathrm{mg} \mathrm{L}^{-1}$ para SR (Tabela 2). A pequena diferença encontrada entre as concentrações efluentes indica que a camada de RCC não proporcionou aumento na remoção de $\mathrm{Cu}$ do percolado. Comportamento semelhante, de baixa mobilidade do elemento $\mathrm{Cu}$, foi verificado por Matos et al. (1996) em latossolos com tratamentos com e sem calagem.

Apesar da pequena diferença encontrada entre as concentrações efluentes das colunas CR e SR (Tabela 2), os percentuais lixiviados, ao longo do período de experimentação, apresentaram comportamentos diferentes. Nas colunas SR, o percentual de dessorção apresentou comportamento uniforme, com os valores de cobre lixiviado em torno de $0,77 \%$ desde o inicio do experimento. Entretanto, nas colunas CR, a porcentagem de lixiviação iniciou-se em valores menores que $0,15 \%$ seguida de picos com maiores lixivições, aproximadamente $1,60 \%$, permanecendo com valores próximos a este até o final do experimento.

No que se refere ao chumbo, os percentuais retidos no material de preenchimento das colunas CR e SR foram, respectivamente, 94,36 e 97,01\% (Tabela 3). Siqueira (1988) encontrou percentual de retenção de chumbo em ácidos húmicos, sob pH 6,5, de 99,8\%. Lamim (1995), variando o $\mathrm{pH}$ de 4,25 a 10,00, obteve percentual de $\mathrm{Pb}$ adsorvido sempre acima de $88,7 \%$ em vermicomposto de esterco bovino. O mesmo autor constatou que a presença de íons competidores do $\mathrm{Pb}$ não afetou em mais que $13 \%$ a adsorção desse elemento.

Os dados apresentados na Tabela 2 mostram que não houve diferença na adsorção de $\mathrm{Pb}$, no que se refere à presença ou não de RCC, e que em ambos os tratamentos a dessorção foi insignificante. Corroborando a baixíssima dessorção do Pb, obtida neste trabalho, Pierangelli (1999) observou que, do total de Pb adsorvido por 17 solos estudados, após reações repetidas num período de 33 dias, em média, menos de 1\% foi dessorvido, após 72 horas de reação com $\mathrm{Ca}\left(\mathrm{NO}_{3}\right)_{2}$, nessas condições experimentais.

Matos et al. (1996) e Pierangeli et al. (2001) não encontraram variações nas quantidades de $\mathrm{Pb}$ adsorvidas nas amostras de latossolos que receberam ou não calagem ou em mudanças na força iônica da solução de equilíbrio. Segundo os autores, isso indica que o $\mathrm{Pb}$ é adsorvido predominantemente como complexos de esfera interna e, pelo menos em curto prazo, oferece menor risco potencial de contaminação ambiental quando comparado a outros metais. Acredita-se que a alta afinidade do $\mathrm{Pb}$ com o RSU velho tenha se dado, como também verificado por Calace et al. (2001), pela diversidade de composição do material, que apresenta não uma particular fração para retenção e, sim, a presença de várias frações simultâneas. A adsorção desse metal no material de preenchimento das colunas foi praticamente constante em quase todo o período experimental, nos dois tratamentos.

Alguns fatos evidenciados neste estudo foram também reportados na literatura. Costa (1991), estudando a competição entre metais por ácidos húmicos, comprovou que, em geral, o $\mathrm{Cu}$ e o $\mathrm{Pb}$ foram mais retidos pelas moléculas de ácidos húmicos do que o $\mathrm{Zn}$ e o $\mathrm{Cd}$, tendo sido o $\mathrm{Cu}$ o elemento mais retido $(95,89 \%$, sob $\mathrm{pH}$ 8,5). A elevada correlação entre as adsorções de $\mathrm{Cu}$ e $\mathrm{Pb}$ também foi verificada em estudo analisando solos de estados 
GUTIERREZ, K. G.; MATOS, A. T.; ROSSMANN, M. Influência da presença de camada de resíduos de construção civil na remoção de metais pesados em percolado recirculado de aterro sanitário. Ambi-Agua, Taubaté, v. 5, n. 2, p. 87-98, 2010. (doi:10.4136/ambi-agua.139)

americanos, onde solos que adsorviam grande quantidade de $\mathrm{Pb}$ também adsorviam grande quantidade de $\mathrm{Cu}$ (Harter, 1979 apud Sousa et al., 2002). Siqueira (1988), estudando a capacidade de retenção dos metais $\mathrm{Cd}, \mathrm{Pb}$, Cu e $\mathrm{Zn}$ por ácidos húmicos, verificou que o pH, tipo de metal, quantidade de metal adicionado e presença de outros cátions metálicos influenciaram significativamente essa reação. O autor constatou ainda que a adsorção de chumbo foi semelhante à adsorção de cobre e não sofreu interferência na presença de cádmio e zinco, em concordância com os resultados encontrados neste estudo.

A Deliberação Normativa COPAM/CERH n ${ }^{\circ} 46$ de 2008, válida para o Estado de Minas Gerais, determina que o percolado tratado deva possuir DBO menor ou igual a $60 \mathrm{mg} \mathrm{L}^{-1}$, ou que o sistema de tratamento utilizado tenha eficiência média anual igual ou superior a $70 \%$ na remoção dessa variável, desde que não venha a prejudicar a qualidade da água de tal forma a suplantar padrões para a sua classe de enquadramento. Na mesma deliberação ficou estabelecido que para o lançamento do efluente em corpos d'água o $\mathrm{pH}$ deve estar em um intervalo de 5 a 9. Neste estudo, tanto a DBO quanto o pH atenderam a referida legislação, tendo a DBO apresentado redução global próxima a 99,5\% e pH próximo a 7,7 para os efluentes de ambos os tratamentos.

No que diz respeito à concentração de metais pesados, na Tabela 4 estão apresentados os padrões referenciais, estabelecidos pela Deliberação Normativa COPAM/CERH n ${ }^{\circ} 46$ de 2008. De acordo com o observado, o sistema de tratamento por recirculação do percolado foi eficiente na remoção de chumbo e cobre, mas não na remoção de cádmio e zinco (Tabela 4). Dessa forma, os efluentes obtidos por recirculação do percolado nas colunas, independente de possuir ou não camada de RCC, não estavam em condições de lançamento em corpos d’água.

Tabela 4. Padrões para lançamento de efluentes em corpos hídricos, segundo a Deliberação Normativa COPAM/CERH n ${ }^{\circ} .01 / 2008$ e concentração efluente nas colunas de tratamento de percolado.

\begin{tabular}{l|ccc}
\hline \multicolumn{1}{c|}{ Metal } & COPAM/CERH n ${ }^{\mathbf{0} .01 / 2008}$ & Efluente CR $^{\mathbf{1}}$ & Efluente SR $^{\mathbf{2}}$ \\
\hline \multirow{3}{*}{$\mathrm{Pb}$ total } & $\leq 0,1$ & $0,024^{*}$ & $0,022^{*}$ \\
Cu dissolvido & $\leq 1,0$ & $0,57^{*}$ & $0,53^{*}$ \\
Cd total & $\leq 0,1$ & $0,29^{*}$ & $0,27^{*}$ \\
Zn total & $\leq 5,0$ & $246,59^{*}$ & $139,23^{*}$ \\
\hline
\end{tabular}

* valores médios;

${ }^{1}$ percolado das colunas experimentais preenchidas com RSU velho com camada de RCC;

2 percolado das colunas experimentais preenchidas com RSU velho sem camada de RCC.

\section{CONCLUSÕES}

À exceção do $\mathrm{Cd}$ e do $\mathrm{Zn}$, todas as outras variáveis avaliadas nos efluentes estiveram abaixo dos padrões estabelecidos na Deliberação Normativa COPAM/CERH, no que se refere ao lançamento de percolados tratados em corpos hídricos. Apesar disso, o sistema de tratamento com a recirculação de percolado de RSU novo em colunas de RSU velho mostrouse eficiente na remoção de poluentes, já que as concentrações afluentes de metais pesados foram 10 vezes maiores do que as encontradas no percolado produzido em aterros sanitários, e sendo as colunas de RSU avaliadas de apenas 2,1 m de altura, inferior ao que é normalmente encontrado em situações práticas. Além disso, a camada de RCC mostrou-se importante para a melhoria geral da qualidade do percolado recirculado em colunas de RSU. 


\section{REFERÊNCIAS}

ALVES, N. M. Adsorção de íons $\mathbf{C u}^{2+}$ em Latossolo vermelho-amarelo húmico e ácidos húmicos de origem comercial. 1998. 83f. Dissertação (Mestrado em Agroquímica) Universidade Federal de Viçosa, Viçosa, MG, 1998.

ANGULO, S. C.; KAHN, H.; JOHN, V.; ULSEN, C. Metodologia de caracterização de resíduos de construção e demolição. In: SEMINÁRIO DESENVOLVIMENTO SUSTENTÁVEL E A RECICLAGEM NA CONSTRUÇÃO CIVIL - MATERIAIS RECICLADOS E SUAS APLICAÇÕES, 6., 2003, São Paulo. Anais... São Paulo: IBRACON: , 2003. 14 p.

AMERICAN WATER WORKS ASSOCIATION; AMERICA PUBLIC HEALTH ASSOCIATION; WORLD ECONOMIC FORUM - AWWA/ APHA/ WEF. Standard methods for the examination of water and wastewater. 21. ed. Washington, D.C.: APHA, 2005. 1368p.

BERTONCINI, E. I. Mobilidade de metais pesados em solos tratados com lodo de esgoto. 1997. 90f. Dissertação (Mestrado em Agronomia) - Escola Superior de Agricultura “Luiz de Queiroz” - ESALQ, Universidade de São Paulo, Piracicaba, 1997.

CALACE, N.; LIBERATORI, A.; PETRONIO, B. M.; PIETROLETTI, M. Characteristics of different molecular weight fractions of organic matter in landfill leachate and their role in soil sorption of heavy metals. Environmental Pollution, v. 113, p. 331-339, 2001.

CARVALHO, A. L. Efeitos da recirculação do percolado sobre a qualidade do efluente de lixo doméstico de diferentes idades. 2005. 115f. Tese (Doutorado em Engenharia Agrícola) - Universidade Federal Viçosa, Viçosa, MG, 2005.

CONSELHO ESTADUAL DE POLÍTICA AMBIENTAL; CONSELHO ESTADUAL DE RECURSOS HÍDRICOS DE MINAS GERAIS. Deliberação Normativa Conjunta COPAM/CERH-MG N. ${ }^{0}$, de 05 de mai. de 2008. Dispõe sobre a classificação dos corpos de água e diretrizes ambientais para o seu enquadramento e estabelece as condições e padrões de lançamento de efluentes. Belo Horizonte: COPAM, 2008.

COSTA, E. D. Adsorção e competição de alguns metais por ácidos húmicos extraídos de um latossolo húmico da região de Araponga, Minas Gerais. 1991. 71f. Dissertação (Mestrado em Agroquímica) - Universidade Federal de Viçosa, Viçosa, MG, 1991.

D’ALMEIDA, M. L. O.; VILHENA, A. Lixo municipal: manual de gerenciamento integrado. 2. ed. São Paulo-SP: IPT/CEMPRE, 2000. 370 p.

EGREJA FILHO, F. B. Avaliação da ocorrência e distribuição química de metais pesados na compostagem de lixo domiciliar urbano. 1993. 176f. Dissertação (Mestrado em Agroquímica) - Universidade Federal de Viçosa, Viçosa, MG, 1993.

ERSES, S. A.; ONAY, T. T. In situ heavy metal attenuation in landfills under methanogenic conditions. Journal of Hazardous Materials, v. B99, p. 159-175, 2003.

FONTES, M. P. F.; GOMES, P. C. Simultaneous competitive adsorption of heavy metals by the mineral matrix of tropical soils. Applied Geochemistry, v. 8, p. 795-804, 2003.

JUNKES, M. B. Procedimento para aproveitamento de resíduos sólidos urbanos em municípios de pequeno porte. 2002. 116f. Dissertação (Mestrado em Engenharia de Produção) - Universidade Federal de Santa Catarina, Florianópolis, 2002. 
GUTIERREZ, K. G.; MATOS, A. T.; ROSSMANN, M. Influência da presença de camada de resíduos de construção civil na remoção de metais pesados em percolado recirculado de aterro sanitário. Ambi-Agua, Taubaté, v. 5, n. 2, p. 87-98, 2010. (doi:10.4136/ambi-agua.139)

KIEHL, E. J. Fertilizantes orgânicos. Piracicaba: Agronômica Ceres, 1985. 492p.

LAMIM, A. P. B. Caracterização de turfa litorânea e estudo de adsorção competitiva de cádmio, cobre, chumbo e zinco. 1988. 118f. Dissertação (Mestrado em Agroquímica) Universidade Federal Viçosa, Viçosa, MG, 1995.

LAMIM, S. S. M.; JORDAO, C. P.; BRUNE, W. Caracterização química e física de vermicomposto e avaliação de sua capacidade em adsorver cobre e zinco. Química Nova, v. 21, n. 3, p. 278-283, 1998.

LAMIM, A. P. B.; JORDAO, C. P.; BRUNE, W.; PEREIRA, J. L.; BELLATO, C. R. Caracterização química e física de turfa litorânea e avaliação da adsorção competitiva por cobre e zinco. Química Nova, v. 24, n. 1, p. 18-23, 2001.

LEAHY, J. G.; SHREVE, G. S. The effect of organic carbon on the sequential reductive dehalogenation of tetrachloroethylene in landfill leachates. Water Research, v. 34, n. 8, p. 2390 - 2396, 2000.

MATOS, A. T.; CARVALHO, A. L.; AZEVEDO, I. C. D. D.; AZEVEDO, R. F. Remoção de poluentes de percolados recirculados em colunas de resíduos sólidos urbanos, em ausência e presença de camada de resíduos da construção civil. Engenharia na Agricultura, v. 17, p. 93-101, 2009.

MATOS, A. T. Fatores de retardamento e coeficientes de dispersão-difusão do zinco, cádmio, cobre e chumbo em solos do município de Viçosa - MG. 1995. 110f. Tese (Doutorado em Solos e Nutrição de Plantas) - Universidade Federal Viçosa, Viçosa, MG, 1995.

MATOS, A. T.; BRANDÃO, V. S.; NEVES, J. C. L.; MARTINEZ, A. A. Removal of Cu and $\mathrm{Zn}$ from swine raising wastewater using organic filters. Environmental Technology, v. 24, p. 171-78, 2003.

MATOS, A. T.; FONTES, M. P. F.; COSTA, L. M.; JORDÃO, C. P.; MARTINEZ, M. A. Mobilidade e formas de retenção em Latossolo vermelho-amarelo. Revista Brasileira de Ciência do Solo, Campinas, v. 20, p. 379-386, 1996.

MOREIRA, D. A. Adsorção de cobre (II), níquel (II) e zinco (II) de efluentes de galvanoplastia por vermicomposto. 2004. 69f. Dissertação (Mestrado em Agroquímica) - Universidade Federal de Viçosa, Viçosa, MG, 2004.

NASCENTES, C. R. Coeficiente de dispersão hidrodinâmica e fator de retardamento de metais pesados em solo residual compactado. 2003, 131f. Dissertação (Mestrado em Geotecnia Ambiental) - Departamento de Engenharia Civil, Universidade Federal de Viçosa, Viçosa, MG, 2003.

OLIVEIRA, F. C.; MATTIAZZO, M. E. Mobilidade de metais pesados em um Latossolo Amarelo distrófico tratado com lodo de esgoto e cultivado com cana-de-açúcar. Scientia Agricola, Piracicaba, v. 58, n 4, p. 807-812, 2001. 
OMAE, S. Adsorção de cádmio em solo podzólico vermelho-amarelo orto, glei húmico da região do Vale do Ribeira, $\mathrm{SP}$, e terra roxa estruturada, do município de Piracicaba, SP. 1984. 41f. Dissertação (Mestrado) - Escola Superior de Agricultura “Luiz de Queiroz” - ESALQ, Universidade de São Paulo, Piracicaba, 1984.

PIERANGELI, M. A. P. Chumbo em latossolos brasileiros: adsorção e dessorção sob efeito de pH e força iônica. 1999. 108f. Dissertação (Mestrado em Agronomia) - Universidade Federal de Lavras, Lavras, 1999.

PIERANGELI, M. A. P.; GUILHERME, L. R. G.; CURI, N.; SILVA, M. L. N.; OLIVEIRA, L. R.; LIMA, J. M. Teor total e capacidade máxima de adsorção de chumbo em Latossolos brasileiros. Revista Brasileira de Ciência do Solo, Campinas, v. 25, p. 279288, 2001.

QASIM, S. R.; CHIANG, W. Sanitary landfill leachate: generation, control and treatment. Lancaster: Technomic Publ., 1994, 339 p.

SILVA, A. C. Tratamento do percolado de aterro sanitário e avaliação da toxicidade do efluente bruto e tratado. 2002. 111f. Tese (Mestrado em Engenharia Civil) Universidade Federal do Rio de Janeiro, Rio de Janeiro, 2002.

SIQUEIRA, R. N. B. Competição e extração seletiva de íons metálicos associados a ácidos húmicos. 1988. 82f. Dissertação (Mestrado em Agroquímica) - Universidade Federal de Viçosa, Viçosa, MG, 1988.

SOUSA, H. A.; ROESER, H. M. P.; MATOS, A. T. Métodos e técnicas aplicados na avaliação ambiental do aterro BR-040 da Prefeitura Municipal de Belo Horizonte MG. Revista Escola de Minas, Ouro Preto, v. 55, n. 4, p. 291-300, 2002. 